\title{
CT-Guided High-Level Percutaneous Cervical Cordotomy for Intractable Cancer Pain
}

\author{
Ahmet BEKAR ${ }^{1}$, M Ozgur TASKAPILIOGLU ${ }^{1}$, Pinar ESER ${ }^{1}$, Hulya BILGIN² \\ 'Uludag University, School of Medicine, Department of Neurosurgery, Bursa, Turkey \\ ${ }^{2}$ Uludag University, School of Medicine, Department of Anesthesiology, Bursa, Turkey
}

\section{ABSTRACT}

AIM: To evaluate the safety and effectiveness of computed tomography-guided high-level percutaneous selective cervical cordotomy (CT-guided HPSCC).

MATERIAL and METHODS: CT-guided percutaneous procedures were performed in fifty-nine patients between the years 20042013 for cancer pain. Forty-eight patients with cancer-related body pain were treated with CT-guided HPSCC was evaluated retrospectively.

RESULTS: CT-guided HPSCC was performed in 33 male and 15 female patients. The mean age was 49.93 years. The distance between skin-dura, anteroposterior diameter and mediolateral diameter was measured as 40 to $71.1 \mathrm{~mm}, 8$ to $88 \mathrm{~mm}$ and 8 to 99 $\mathrm{mm}$ respectively. The mean postoperative Karnofsky Performance Score (KPS) was 95. Mean preoperative Visual Analog Scale (VAS) score was 9.6 , and 3.6 on postoperative day 1. The $6^{\text {th }}$ month follow-up VAS score was 6.8 . Preoperative total sleeping hours in a 24-hour period were 5.5 hours, which increased in the immediate postoperative period to 8.5 hours. The most common pathology treated was bronchogenic carcinoma. Six of the procedures were bilateral and there were no permanent complication due to the procedure.

CONCLUSION: CT-guided HPSCC is still very effective, cheap and repetitive procedure for cancer pain. The procedure should be performed by experienced surgeons and although there is a hegemony of opioids, the number of surgeons that perform the procedure must be increased.

KEYWORDS: Cancer pain, Cervical cordotomy, Computed tomography-guided cordotomy

\section{INTRODUCTION}

A meliorations in the medicine prolong the life of cancer patients. However, as they live longer, more patients with malignancy in the terminal stage will probably have intractable pain (4). Systemic analgesia provided by narcotics is the first choice of treatment for relieving pain generally. If the patient does not respond to narcotics, ablative procedures such as tractotomy, cordotomy or myelotomy must be considered. Cordotomy is generally useful for the patients with a limited life expectancy (29). The cancer pain incidence ranges from 20 to $50 \%$ in all patients in early cancer stages to 55 to $95 \%$ in later stages (20). The procedure is generally useful for unilateral nociceptive pain.

The percutaneous technique was introduced by Mullan in 1963 (17). In 1965, Rosomoff et al. used radiofrequency (RF) current to produce a lesion (23). Kanpolat described the usage of CT-guided HPSCC $(5,9)$. However, the broad use of intraspinal narcotics has affected the use of spinal cord ablation procedures, but CT-guided percutaneous cervical cordotomy (PCC) is still the most effective procedure for patients with unilateral intractable pain. 
The purpose of this study was to evaluate the safety and effectiveness of CT-guided HPSCC.

\section{MATERIAL and METHODS}

The clinical and functional outcome of the forty-eight patients treated with CT-guided HPSCC between the years 2004-2013 was evaluated and analyzed.

For study inclusion, patients had to meet the following criteria: 1) histopathological diagnosis; 2) pain duration $\geq 1$ month; 3 ) a KPS > 40;4) an estimated life expectancy of more than 3 months; 5) absence of bleeding tendency.

Pain intensity was assessed by the surgeon or the surgical team preoperatively using a VAS, and the total duration of sleep uninterrupted by pain was recorded. Patients were further evaluated using the KPS. Patient postoperative evaluation included VAS, total sleeping hours, and pain scale (Scores were recorded as I, no pain; II, almost no pain or partial but satisfactory pain relief; III, partial, unsatisfactory pain relief; IV, same; V, worse) at postoperative day 1 and 6 months (20). Patients were also evaluated for possible complications in the postoperative period.

\section{CT-guided HPSCC Technique}

The surgical procedure was performed as described before by Kanpolat et al. $(5,6,8,12)$. The procedure was performed in a computed tomography unit. To rule out mass lesions, cranial magnetic resonance imaging was performed in all patients. The patient was placed on the CT table in the supine position. The patient's head was kept in flexion with the help of a head support. CT images with $2 \mathrm{~mm}$ slice thickness were used. A cordotomy needle (Radionics, Inc, Burlington, Mass) was used in all procedures for CT-guided HPSCC procedures. The straight electrode was used to make the ablative lesion at the lateral spinothalamic tract. Thermocouple sensor at the electrode tip measured the temperature to confirm that a lesion is truly being made (11). The target of the procedure, lateral spinothalamic tract, was located in the anterolateral region of the spinal cord at the $\mathrm{C} 1-\mathrm{C} 2$ level. Before the procedure, the dimensions of the spinal cord were determined for each patient. lohexol (7-8 mL, $240 \mathrm{mg} / \mathrm{mL}$ ) was administered 20 to 30 minutes before the operation intrathecally $(5,12)$. After the local anesthetic agent, the cordotomy needle was inserted inferior to the mastoid process in the vertical plane perpendicular to the axis of the spinal cord (12). The anterolateral part of the dura of the spinal canal was the ideal placement of the needle. Using repeated slices. the ideal position for cannula was determined. The ideal localization of the cannula tip was $1 \mathrm{~mm}$ anterior to the denticulate ligament for lumbosacral fibers and 2 to $3 \mathrm{~mm}$ anterior to the denticulate ligament for thoracic and cervical fibers after the puncture $(9,12)$. The needle was in the ideal position if it is nearly perpendicular to the spinal cord. After achieving the ideal position of the needle tip, the straight electrode (0.27-mm diameter and 2-mm open-tip electrode; Radionics, Inc., Burlington, Mass, USA) was inserted (Figure 1). The functional response was confirmed with impedance measurement and stimulation. The impedance was measured as $100-200 \Omega$ in the cerebrospinal fluid, $300-400 \Omega$ in contact with the spinal cord and $800-1000 \Omega$ inside the spinal cord. The patient's compliance is crucial for this procedure. If the electrode is located in the target, $100-\mathrm{Hz}$ stimulation gives a response around $0.2 \mathrm{~V}(12,14)$. The energy and tip temperature of the active electrode were continuously monitored. Motor functions, pain perception, and discrimination of hot and cold sensation were tested peroperatively and postoperatively. The mean duration of procedure was approximately $40 \mathrm{~min}$.

A VAS was used for the pain score, total sleeping hours were measured and the KPS was used to determine the performance status of the patients.

\section{RESULTS}

The procedure was performed in 33 male and 15 female patients. Most patients were at the $5^{\text {th }}$ or $6^{\text {th }}$ decade (range, 3 7-71 yr; mean 49.93 $\pm 11.37 \mathrm{yr}$ ). The distance between skindura, anteroposterior diameter and mediolateral diameter was measured as 40 to $71.1 \mathrm{~mm}$ (mean, $49.8 \mathrm{~mm}$ ), 8 to $88 \mathrm{~mm}$ (mean, $15.69 \mathrm{~mm}$ ), 8 to $99 \mathrm{~mm}$ (mean, $21.2 \mathrm{~mm}$ ) respectively at the occiput-C1 level, C1-C2 level (Table I). Surgical outcome was evaluated by KPS, and VAS was used for pain and sleeping hours (Table II). The mean preoperative KPS was 78.1 , and the mean postoperative KPS was 95. Mean preoperative VAS score was 9.6, and 3.6 on postoperative day 1 . The $6^{\text {th }}$ months follow-up VAS score was 6.8. Total sleeping hours were also significantly improved. Preoperative total sleeping hours in a 24-hour period were 5.5 hours, which increased in the immediate postoperative period to 8.5 hours. Considering the 27 patients that survived more than 6 months, the 6 months follow-up mean sleeping hours gradually decreased to 7 hours but still remained statistically significant compared with the preoperative value $(p=0.0002)$. The most common pathology treated was bronchogenic carcinoma (41.6\%); other pathologies treated are outlined in Table III.

Transient paresis was observed in one patient after the operation and ameliorated within one week. Satisfactory hypoesthesia was obtained in all patients. Sleep apnea related to the

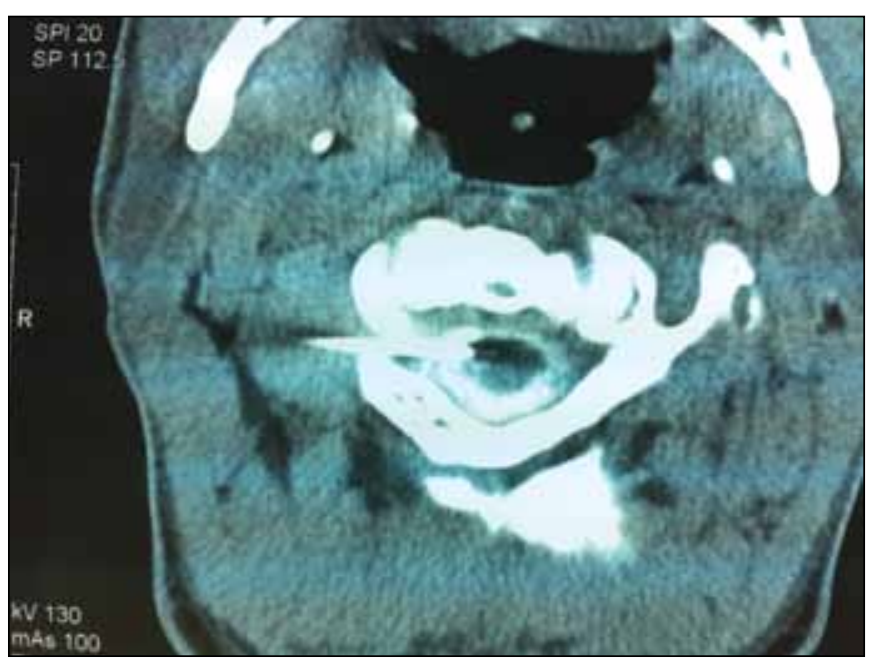

Figure 1: Computerized tomography scan showing the needle and electrode in their final position. 
Table I: Summary of Data Measured

\begin{tabular}{lccc}
\hline & Minimum & Maximum & Mean + SD \\
\hline Skin dura distance $(\mathrm{mm})$ & 40 & 71.1 & $49.8 \pm 4.85$ \\
\hline Anteroposterior cord diameter $(\mathrm{mm})$ & 8 & 88 & $15.69 \pm 21.83$ \\
\hline Mediolateral cord diameter $(\mathrm{mm})$ & 8 & 99 & $21.2 \pm 29.2$ \\
\hline
\end{tabular}

Table II: Pain Surgery Outcome

\begin{tabular}{|c|c|c|c|c|}
\hline & & Minimum value & Maximum value & Mean \\
\hline \multirow[t]{2}{*}{ Karnofsky Performance Scale } & Preoperative & 50 & 100 & $78.12 \pm 15.12$ \\
\hline & Immediate postoperative & 90 & 100 & $95 \pm 5.4$ \\
\hline \multirow[t]{3}{*}{ Visual Analog Scale } & Preoperative & 7 & 10 & $9.6 \pm 0.8$ \\
\hline & Immediate postoperative & 0 & 6 & $3.9 \pm 0.7$ \\
\hline & Postoperative 6 months & 1 & 8 & $2.3 \pm 0.7$ \\
\hline \multirow[t]{3}{*}{ Total sleeping hours } & Preoperative & 1 & 12 & $5.5 \pm 2.6$ \\
\hline & Immediate postoperative & 5 & 12 & $8.5 \pm 2.1$ \\
\hline & Postoperative 6 months & 2 & 8 & $4.8 \pm 0.8$ \\
\hline
\end{tabular}

Table III: Pathology of Patients

\begin{tabular}{lcc}
\hline Pathology & Number & $\%$ \\
\hline Bronchogenic Ca & 20 & 41.6 \\
\hline Colon Ca & 5 & 10.4 \\
\hline Mesothelioma & 4 & 8.3 \\
\hline Pancoast tumor & 4 & 8.3 \\
\hline Prostate Ca & 3 & 6.2 \\
\hline Mesenchymal sarcoma & 3 & 6.2 \\
\hline Vulva cancer & 2 & 4.1 \\
\hline Rectal cancer & 2 & 4.1 \\
\hline Adenoid cystic carcinoma & 2 & 4.1 \\
\hline Breast cancer & 1 & 2.0 \\
\hline Chordoma & 1 & 2.0 \\
\hline Pharynx cancer & 1 & 2.0 \\
\hline
\end{tabular}

procedure was not encountered. Dysesthesia occurred in 7 patients undergoing cordotomy and persisted in 5 patients, but completely resolved by the first month follow-up assessment. One unilateral cordotomy patient had transient urinary retention that completely improved after one month.

\section{DISCUSSION}

The incidence of cancer and degenerative diseases has increased especially during the last decade. Intrathecal opioids are the current trend for cancer pain management.
The concept of sectioning pain-carrying fibers to relieve pain was first proposed by Spiller (28). In $80 \%$ of patients, pain relief can be provided by the application of the WHO guidelines and co-analgesics. For patients with midline or bilateral pain, continuous spinal infusion techniques are more beneficial for further pain control (3). For the remaining $20 \%$, if the pain is located unilaterally, cordotomy can be a good option $(24,27)$.

Pulmonary malignancies, mesothelioma, Pancoast tumors, gastrointestinal carcinoma, and metastatic carcinoma are the most commonly treated pathologies (13). The procedures have also been performed to relieve pain from noncancerous causes such as electrical burns, postherpetic neuralgia, tuberculosis, phantom limb pain, cauda equina injury, radiculopathy, joint pain, arachnoiditis, unsuccessful back surgery, and gunshot trauma (2). In this manuscript we only evaluated the patients suffering from intractable cancer pain.

CT-guided unilateral or bilateral selective cordotomy may control unilateral upper body pain (secondary to lung carcinoma, mesothelioma, or Pancoast tumors) and bilateral somatic intractable pain in the lower body and extremities (1). The somatotropic segmentation of the spinothalamic tract provides the opportunity for selective cordotomy and is used particularly for bilateral lesioning to denervate the sacral and lumbar area (bilateral selective cordotomy) (1). Bilateral selective cordotomy is not widely used because of the close proximity to the reticulospinal tract and the risk of sleep-induced apnea (26). We performed four bilateral CTguided HPSCC procedures without causing any pulmonary dysfunction.

Patients with lung mesothelioma and pulmonary carcinoma are accepted as high-risk patients for radiographically-guided cordotomy. In a prospective study, Price et al. reported that 
Bekar A. et al: Cordotomy for Pain

Table IV: Patient Pain Relief Postprocedure

\begin{tabular}{cccr}
\hline Scale & Pain & Immediate postoperative & Postoperative 6 $^{\text {th }}$ month \\
\hline I & No pain & $35(72.9 \%)$ & $21(43.7 \%)$ \\
\hline II & Partial satisfactory pain relief & $12(25.0 \%)$ & $24(50.0 \%)$ \\
\hline III & Partial nonsatisfactory pain relief & $1(2.0 \%)$ & $3(6.2 \%)$ \\
\hline IV & No change in pain & 0 & 0 \\
\hline V & Worse pain & 0 & 0 \\
\hline
\end{tabular}

cordotomy as a safe and well-tolerated procedure even in patients with impaired respiratory function tests (19). These patients can be treated successfully with the guidance of CT (10). There were 24 patients with bronchogenic carcinoma and mesothelioma in our series and all tolerated the procedure well.

Kanpolat et al. measured the transverse distance as 9.3 to $14 \mathrm{~mm}$ and the anteroposterior distance as 7.0 to $12.8 \mathrm{~mm}$ (7). Raslan found the skin-dura distance as 43 to $56 \mathrm{~mm}$. We measured the distance between the dura and the skin at the level of occiput-C1 as 40 to $71.1 \mathrm{~mm}$ (mean= $49.8 \mathrm{~mm}$ ) with CT scans (20). 8 to $88 \mathrm{~mm}$ was the anteroposterior distance, and 8 to $99 \mathrm{~mm}$ was the mediolateral cord diameter in our series. The differences between the studies may be the result of more precise measurements with newer CT machines.

Raslan and Nauta et al. reported an improvement in the mean KPS scores after cordotomies and myelotomies in patients with cancer pain $(18,20)$. The authors pointed that the KPS reflects the overall functional status and as such was not measured in subsequent follow-up visits generally because other aspects of disease progression not necessarily related to pain control may skew results. Similar to the literature, the mean preoperative KPS was 78.1 and improved to 95 at early postoperative period in our series.

Disadvantages of cordotomy are the limited duration of pain relief, with recurrence of symptoms often within 1 year (22). In a review of 5770 cases whose pain relief was independently evaluated, at least $75 \%$ of cancer patients reported pain relief for 6 months (28). In a retrospective study, Raslan found a statistically significant reduction in VAS after cordotomy that sustained during the 6- month follow-up (20). There was a significant reduction in VAS in our series (Table IV), in line with Raslan's series.

Total average sleeping hours increased from 3.25 hours to 7 hours in the immediate postoperative period and at 6-months follow-up. Total sleeping hours were 4.78 hours in Raslan's series (20). Sleeping progressed from 5.5 hours to 7 hours at 6 months follow-up in our series.

Ondine's curse, failure of unconscious respiration after ablation of the reticulospinal tract especially after bilateral selective cordotomy, ipsilateral motor weakness, ataxia, bladder dysfunction, Horner's syndrome, sexual impotence, unmasking pain on the opposite side of the body, exacerbation of pain at other sites and general fatigue are the expected com- plications of cordotomy $(2,12,28)$. We observed none of these complications in our series.

In Lahuerta's series of over 100 cases that underwent cordotomy, the mortality rate was $6 \%$. Ipsilateral leg weakness was observed in $69 \%$ and urinary retention in $20 \%$ of the cases (15). Motor complications ranged from zero to $17 \%$ in unilateral procedures and permanent urinary disturbances were found only after bilateral procedures (22\%) in Sindou's review (25). There was one transient urinary retention with unilateral cordotomy patient in our series.

Lorenz and Sindou et al. stated that cordotomy is an effective procedure, but it carried a risk of $0 \%$ to $9 \%$ mortality and morbidity at their collected series $(16,25)$. Contrary to the criticism of Sindou et al., Kanpolat et al. pointed to the possibility of repeating the procedure in case of pain relief over time (12). There was no mortality in our series.

Kanpolat et al. reported no mortality or major morbidity in their large series (12). The authors reported temporary slight motor paralysis in $5(2.4 \%)$ cases and also $5(2.4 \%)$ cases of temporary ataxia. The only permanent complication was postcordotomy dysesthesia in 4 cases (1.9\%) reported in this series and they reported $92.5 \%$ success rate while emphasizing the experience of the surgeon (12).

In a literature review, Raslan et al. examined 3601 patients and pointed that there were no Class I reports (21). In a prospective study, the author reported a statistically significant improvement in all outcome measures that compared postprocedure pain levels with baseline (20). None of the prospective papers or the retrospective cohorts qualified as Class II evidence even though the quality of data were higher than that of conventional Class III literature (21).

\section{CONCLUSION}

CT-guided HPSCC is still very effective, cheap and repeatable procedure for cancer pain. The procedure should be performed by experienced surgeons. Although there is a hegemony of opioids, the number of surgeons that performed the procedure must be increased.

\section{ACKNOWLEDGEMENT}

The authors would like to thank our teacher Prof. Dr. Yücel Kanpolat, pioneer of cordotomy, for his inspiration and Prof. Dr. Ali Savaş for his valuable criticism of the manuscript. 


\section{REFERENCES}

1. Bekar A, Kocaeli H, Abas F, Bozkurt M: Bilateral high-level percutaneous cervical cordotomy in cancer pain due to lung cancer: A case report. Surg Neurol 67:504-507, 2007

2. Collins KL, Taren JA, Patil PG: Four-decade maintenance of analgesia with percutaneous cordotomy. Stereotact Funct Neurosurg 90:266-272, 2012

3. van Dongen RTM, Crul BJP, De Bock M: Long-term intrathecal infusion of morphine/bupivacaine mixtures in the treatment of cancer pain: Analysis of 51 cases. Pain 55:119-123, 1993

4. Hasenbuch SJ: Surgical management of cancer pain. Neurosurg Clin N Am 6:127-134, 1995

5. Kanpolat Y, Deda H, Akyar S, Bilgic S: CT- guided percutaneous cordotomy. Acta Neurochir Suppl (Wien) 46:67-68, 1989

6. Kanpolat Y, Akyar S, Caglar S, Unlu A, Bilgic S: CT guided percutaneous selective cordotomy. Acta Neurochir (Wien) 123: 92-96, 1993

7. Kanpolat Y, Akyar S, Caglar S: Diametral measurements of the upper spinal cord for stereotactic pain procedures: Experimental and clinical study. Surg Neurol 43:478-482, 1995

8. Kanpolat Y, Caglar S, Akyar S, Temız C: CT-guided pain procedures for intractable pain in malignancy. Acta Neurochir (Wien) Suppl 64: 88-91, 1995

9. Kanpolat Y, Savas A, Caglar S, Temiz C, Akyar S: Computerized tomography guided percutaneous bilateral selective cordotomy. Neurosurg Focus 2:e4, 1997

10. Kanpolat Y, Savas A, Ucar T, Torun F: CT-guided percutaneous selective cordotomy for treatment of intractable pain in patients with malignant pleural mesothelioma. Acta Neurochir (Wien) 144:595-599, 2002

11. Kanpolat $Y$ : The surgical treatment of chronic pain: Destructive therapies in the spinal cord. Neurosurg Clin N Am 15:307-317, 2004

12. Kanpolat $\mathrm{Y}$, Ugur HC, Ayten M, Elhan AH: Computed tomography-guided percutaneous cordotomy for intractable pain in malignancy. Neurosurgery 64:187-193, 2009

13. Kanpolat Y, Ozdemir M, Al-Beyati E: CT-guided percutaneous cordotomy for intractable pain in what is more than a disease: Lung malignancies. Turk Neurosurg 23:81-87, 2013

14. Kopell BH, Cosan TE, Ghany WAA, Acık V, Kanpolat Y: CTguided percutaneous cordotomy in a patient with disseminated neurofibromatosis. Turk Neurosurg 16:202-203, 2006

15. Lahuerta J, Bowsher D, Lipton S, Buxton PH: Percutaneous cervical cordotomy: A review of 181 operations on 146 patients with a study on the localization of "pain fibers" in the C2 spinal cord segment of 29 cases. J Neurosurg 80: 975-985, 1994
16. Lorenz R: Methods of percutaneous spinothalamic tract section. In: Krayenbühl $H$, Brihaye J, Loew F, Mingrino S, Pertuiset B, Symon L, Troupp H, Yasargil MG (eds). Advances and Technical Standards in Neurosurgery. Vienna:SpringerVerlag, 1976:123-154

17. Mullan S, Harper PV, Hekmatpanah J, Torres H, Dobbin G: Percutaneous interruption of spinal-pain tracts by means of a strontium needle. J Neurosurg 20:931- 939, 1963

18. Nauta HJ, Hewitt E, Westlund KN, Willis WD Jr: Surgical interruption of a midline dorsal column visceral pain pathway. Case report and review of the literature. J Neurosurg 86:538542,1997

19. Price C, Pounder D, Jackson M, Rogers P, Neville E: Respiratory function after unilateral percutaneous cervical cordotomy. J Pain Symptom Manage 25:459-463, 2003

20. Raslan AM: Percutaneous computed tomography-guided radiofrequency ablation of upper spinal cord pain pathways for cancer-related pain. Neurosurgery 62:226-233, 2008

21. Raslan AM, Cetas JS, McCartney S, Burchiel KJ: Destructive procedures for control of cancer pain: The case for cordotomy. J Neurosurg 114:155-170, 2011

22. Romanelli $\mathrm{P}$, Esposito $\mathrm{V}$, Adler J: Ablative procedures for chronic pain. Neurosurg Clin N Am 15: 335-342, 2004

23. Rosomoff HL, Brown CJ, Sheptak P: Percutaneous radiofrequency cervical cordotomy: Technique. J Neurosurg 23: 639- 644, 1965

24. Sanders M, Zuurmond W: Safety of unilateral and bilateral percutaneous cervical cordotomy in 80 terminally ill cancer patients. J Clin Oncol 13:1509-1512, 1995

25. Sindou M, Jeanmonod D, Mertens $P$ : Ablative neurosurgical procedures for the treatment of chronic pain. Neurophysiol Clin 20:399-423, 1990

26. Taren JA, Davis R, Crosby EC: Target physiologic corroboration in stereotactic cervical cordotomy. J Neurosurg 30:569-584, 1969

27. Tasker RR: Cordotomy for pain. In: Youmans JR, (ed). Neurological Surgery. Philadelphia: Saunders, 1996:34633476

28. Tasker R: Percutaneous cordotomy for persistent pain. In: Gildenberg P, Tasker R (eds). Textbook of Stereotactic and Functional Neurosurgery. New York:McGraw Hill, 1998:14851505

29. Zuurmond WW, Perez RS, Loer SA: Role of cervical cordotomy and other neurolytic procedures in thoracic cancer pain. Curr Opin Support Palliat Care 4:6-10, 2010 